\title{
The association of iron status with educational performance and intelligence among adolescents
}

\author{
D S Dissanayake ${ }^{1}$, P V R Kumarasiri ${ }^{1}$, D B Nugegoda ${ }^{1}$ and D M Dissanayake ${ }^{2}$
}

(Index words: iron status, anaemia, school performance, IQ)

\begin{abstract}
Introduction The aim was to identify the association of iron status with educational performance and intelligence of adolescents.

Method This was a cross sectional comparative study among adolescents aged 13-15 years. Each iron deficient student was matched with an iron sufficient student from the same school, class and sex. Iron status was based on haemoglobin and serum ferritin levels. The marks for mathematics, science, Sinhala language and social science were considered to assess educational performance. Intelligence was measured by Raven's Standard progressive matrices. All the possible confounders and effect modifiers were considered. Home visits to a sub-sample checked the quality of data.

Results The final analysis included 188 students (94 matched pairs). Neither educational performance nor intelligence showed significant associations with the iron status. The severity of the iron deficiency did not relate to these cognitive variables either. Twenty-three and 8 covariables showed statistically significant associations with educational performance and intelligence respectively. Following a multiple regression analysis intelligence, the enthusiasm of the student towards learning, occupational ambition, household possession, problems at home and private tuition for mathematics were key factors predicting educational performance. Stunting and educational level of the mother were important factors influencing intelligence.
\end{abstract}

Conclusion Iron status does not play a major role in educational performance and intelligence of school going adolescents. Several factors affect educational performance and intelligence. This study highlights the difficulty in extrapolating the findings of similar studies to different ecological settings.

\section{Introduction}

Many studies have been carried out to find the association between iron deficiency and cognitive functions in infants and children. There have been studies with controversial conclusions. The generalisability of these research findings to other ecological settings is doubtful. No study has been done in Sri Lanka to find the relationship between iron status and cognitive functions.
Adolescents are a group prone to iron deficiency. Since iron deficiency is correctable, establishing its association with cognitive functions is important. This study was a cross sectional comparative study to determine the association of iron deficiency with educational performance and intelligence among a group of Sri Lankan adolescents.

\section{Methods}

The study included a sample of students who participated in a community based investigation that established the prevalence and determinants of iron deficiency among 13-15-year old adolescents $(n=960)$ in the Kandy district [1]. The sample $(\mathrm{n}=200)$ included only Sinhalese students. They were from 14 different schools.

The haemoglobin level $(\mathrm{Hb})$ was determined by the indirect cyanmethhaemoglobin method, the method considered as the gold standard. The serum ferritin level (SF) [2] was determined by an enzyme linked immuno assay (ELISA). From iron deficient students (SF $\leq 12 \mu \mathrm{g} / \mathrm{l}$ with a normal or low $\mathrm{Hb}$ level), 100 were randomly selected. Each selected iron deficient student was matched with an iron sufficient student from the same school, same class and of the same sex. The procedure of matching controlled many factors that could have possible confounding effects since these pairs would have experienced similar inputs by teachers, and have similar socio-economic backgrounds and other facilities at school. Students with borderline iron stores (SF level of 13-30 $\mu \mathrm{g} / \mathrm{l}$ ) were excluded to minimise the chance of an overlap between iron deficient and iron sufficient groups. All the iron sufficient students had a $\mathrm{Hb}>12 \mathrm{~g} / \mathrm{dl}$ and $\mathrm{SF}>30 \mu \mathrm{g} / \mathrm{l}$. Of the iron deficient students, some suffered from iron deficiency anaemia $(\mathrm{Hb} \leq 12 \mathrm{~g} / \mathrm{dl}$ and $\mathrm{SF} \leq 12 \mu \mathrm{g} / \mathrm{l}$ ) while others had iron deficiency without anaemia $(\mathrm{Hb}>12 \mathrm{~g} / \mathrm{dl}$ and $\mathrm{SF} \leq 12 \mu \mathrm{g} / \mathrm{l})$.

Educational performance was assessed based on the marks obtained for science, mathematics, social science and Sinhala language during the third term test. As all government schools in the Kandy district receive common question papers and marking schemes from the Ministry of Education for the third term test, the marks would have been comparable among different schools. The standard progressive matrices by J. C. Raven was used to determine intelligence. This non-verbal test with a high reliability

${ }^{1}$ Departments of Community Medicine and ${ }^{2}$ Pathology, Faculty of Medicine, University of Peradeniya, Sri Lanka.

Correspondence: DSD, e-mail <devanis/2002@yahoo.com>. Received 15 October 2008 and revised version accepted 7 March 2009. Competing interests: none declared. 
and validity is considered to be one of the best tools to measure general intelligence $[3,4]$. Since the objective of this study was to compare intelligence between 2 groups rather than assessing the intelligence quotient at an individual level, raw scores were used in the analysis.

An interviewer administered questionnaire was used to collect details of factors that could be modifiers or confounders. The principal investigator and 4 other medical doctors collected data. Students as well as class teachers were interviewed. The weight and height were measured to assess protein energy status. In $25 \%$ of the sample (23 iron sufficient and 23 iron deficient), serum zinc and free thyroxin (free $\mathrm{T}_{4}$ ) were measured to determine whether these could be confounders to the relationship between iron status and cognitive functions. Serum zinc levels were analysed by atomic absorption spectrometry and free $\mathrm{T}_{4}$ levels by radio immuno assay (coated bead RIA). Cutoff levels of $700 \mu \mathrm{g} / \mathrm{l}$ and $10 \mathrm{pmol} / \mathrm{l}$ were taken to define zinc deficiency and $\mathrm{T}_{4}$ deficiency level respectively.

Home visits were carried out in a randomly selected sub sample $(n=45)$ to check the quality of data and to observe the influence of the home environment on educational performance and intelligence. All homes were visited by the principal investigator to prevent inter observer variation. Ethical approval for this study was granted by the Committee on Research and Higher Degrees, Faculty of Medicine, Peradeniya.

\section{Results}

The final sample studied consisted of 188 students (94 matched pairs), 124 were girls. Of the 94 iron deficient students, 58 had iron deficiency anaemia (IDA) while 36 had iron deficiency without anaemia (ID without A).

All comparisons were carried out between matched groups. The examination marks obtained by iron sufficient students for individual subjects were not significantly different from those of iron deficient students (Table 1).
The total marks obtained for all 4 subjects by iron sufficient group were also not significantly different from those of the iron deficient group (Table 1). Further analysis was carried out to find whether the severity of iron deficiency has an effect on educational performance. Marks obtained by students with IDA, ID without A, and students with moderate to severe IDA (low $\mathrm{SF}$ and $\mathrm{Hb}<10 \mathrm{~g} / \mathrm{dl}$ ) were compared with marks of matched iron sufficient students. No significant differences in educational performance were observed between groups (Table 2).

Of the co-variables considered, 23 variables showed statistically significant associations with educational performance (Table 3). Controlling for the effects of these associations by linear regression analysis could not elicit a significant relationship between iron status and educational performance. The final model of the multiple regression analysis identified intelligence $(p=0.007)$, enthusiasm paid by the student towards education $(\mathrm{p}<0.001)$, occupational ambition of the student $(\mathrm{p}=0.004)$, the score obtained for household possessions $(p=0.007)$ and obtaining private tuition for mathematics $(\mathrm{p}=0.01)$ as having significant positive associations with educational performance. A significant negative association was noted between educational performance and problems at home $(\mathrm{p}<0.001)$.

No significant relationship was observed between intelligence and iron status (Table 3). Severity of iron deficiency was also not associated with IQ (Table 4). Eight co-variables were significantly associated with intelligence (Table 5). Following a linear regression analysis, the educational level of the mother showed a strong positive association with intelligence $(\mathrm{p}=0.001)$. Stunted children (having a height below 2 standard deviations for their age and sex) had a significantly lower intelligence ( $\mathrm{p}=0.001)$. Nevertheless, multiple regression analysis could not elicit a significant association between iron status and intelligence.

Table 1. Educational performance of iron sufficient and iron deficient students.

\begin{tabular}{lccc}
\hline \multirow{2}{*}{ Subject } & \multicolumn{2}{c}{ Marks according to iron status } & $* p$ value \\
\cline { 2 - 3 } & $\begin{array}{c}\text { Iron sufficient } \\
(n=94)\end{array}$ & $\begin{array}{c}\text { Iron deficient } \\
(n=94)\end{array}$ & \\
\cline { 2 - 3 } & mean $(S D)$ & mean $(S D)$ & \\
\hline Maths & $40.1(25.9)$ & $39.5(25.3)$ & 0.87 \\
Science & $45.5(18.8)$ & $48.6(18.9)$ & 0.25 \\
Sinhala & $55.8(17.4)$ & $58.3(16.7)$ & 0.32 \\
Social Science & $52.0(20.9)$ & $50.9(20.0)$ & 0.71 \\
Total marks & $193.4(69.1)$ & $197.3(66.6)$ & 0.69 \\
\hline
\end{tabular}

* $\mathrm{t}$ test used to determine the significance of difference 


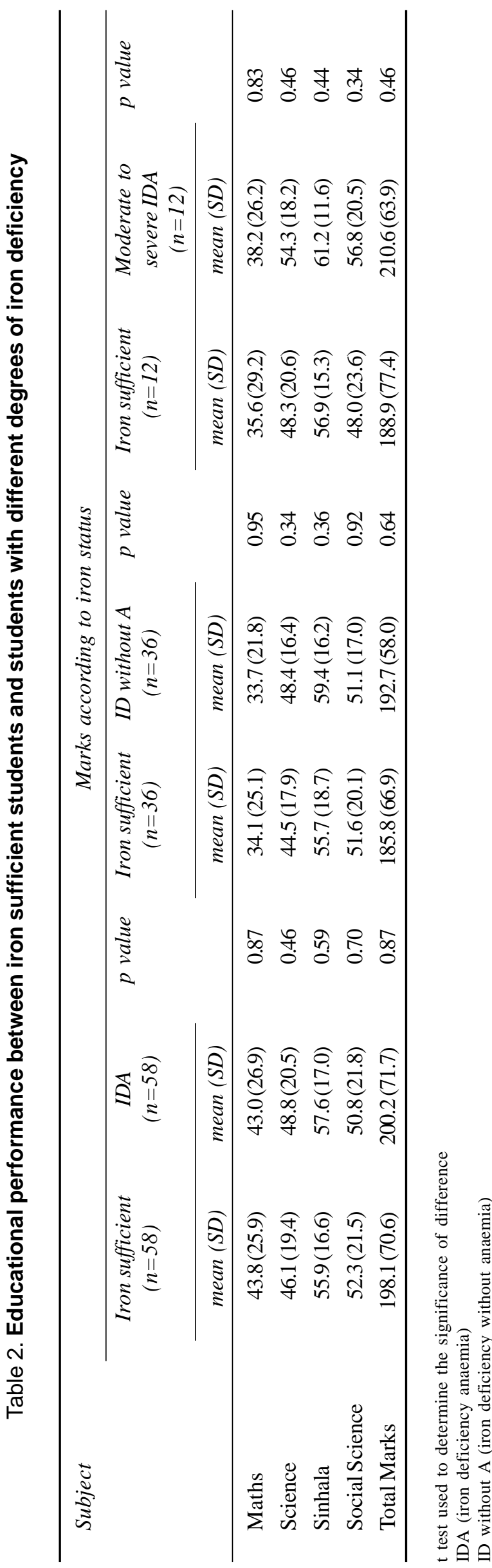

The reliability of the $\mathrm{Hb}$ measurement $(\mathrm{r}=0.74$; $\mathrm{p}<0.001)$ and $\mathrm{SF}$ measurement $(\mathrm{r}=0.91 ; \mathrm{p}<0.001)$ was high. Of the sub sample of 46 , only 6 (13\%) had zinc deficiency. Of iron deficient subjects, $17.4 \%$ had concurrent zinc deficiency. Among iron sufficient subjects, only 8.7\% had zinc deficiency. The difference between proportions was not significant $(\mathrm{p}=0.38)$. Neither educational performance $(\mathrm{p}=0.46)$ nor intelligence $(\mathrm{p}=0.68)$ of the students showed a significant association with their zinc status. Only 4 students had low free $T_{4}$ levels. Of them, 3 were iron deficient. As only 4 students had low thyroxin levels, further analysis was not possible.

Data collected had high validity (sensitivity 68-100\%) and good reliability (Kappa co-efficient 0.67-0.71). During home visits, the ambition of the parents to educate their child, space in the house and the accessibility to the house showed significant positive associations with educational performance. However, none of the factors in the home environment showed a relationship with the intelligence of the students.

\section{Discussion}

According to the findings of our study, it is unlikely that current iron status of adolescents would influence either their educational performance or intelligence.

A clinical trial conducted in Indonesia had shown that educational performance of students having IDA ( $\mathrm{n}=$ 78) was significantly lower than that of students who were non-anaemic and iron sufficient $(\mathrm{n}=41)$ [5]. The study did not find an association between iron status and intelligence. Another trial in Thailand had assessed the impact of iron treatment on intelligence and educational attainment of 9-11 year old children [6]. Though no relationship had been observed between iron status and scores obtained for mathematics, both intelligence and Thai language scores showed significant positive associations with iron status. However, there was no evidence to prove that the association was causal [6]. Though the present study excluded students with diseases that could have influenced the indicators of iron status, both the Indonesian and Thai studies have failed to do so. In addition, the study in Thailand did not exclude students with borderline iron status. Further, the authors have admitted inadequate control for other factors as a shortcoming of their methodology. Both the above studies as well as the current study considered only marks of one test to assess educational performance. This is a limitation of these studies.

A randomised controlled trial among 98 non-anaemic iron deficient adolescent girls has shown that iron supplementation improved verbal learning and memory [7]. In England, results of an interventional study which examined the effect of iron supplementation on intelligence were not in favour of a causal relationship between the two [8]. 
Table 3. Factors associated with educational performance and intelligence

\begin{tabular}{|c|c|c|c|}
\hline \multicolumn{2}{|c|}{ Factors associated with educational performance } & \multicolumn{2}{|c|}{ Factors associated with intelligence } \\
\hline Factor & $p$ value & Factor & $p$ value \\
\hline Father's education & $*<0.001$ & Father's education & $+<0.001$ \\
\hline Mother's education & $*<0.001$ & Mother's education & $+<0.001$ \\
\hline Father's occupation & $*<0.001$ & Father's occupation & $+<0.001$ \\
\hline Mother's occupation & $*<0.001$ & Mother's occupation & $+<0.001$ \\
\hline Possession of household items & $*<0.001$ & Availability of a television & ++0.21 \\
\hline Availability of a television & $* * 0.04$ & Number of siblings in the family & +0.53 \\
\hline Distance to school & $*<0.001$ & Position among siblings & +0.42 \\
\hline Availability of electricity & $* * 0.07$ & $\begin{array}{l}\text { Position among siblings } \\
\text { Mother's presence at home }\end{array}$ & $\begin{array}{r}+0.42 \\
++0.04\end{array}$ \\
\hline Availability of a place to study & $* *<0.001$ & Mother's presence at home & ++0.04 \\
\hline Number of siblings in the family & $* 0.39$ & Extra curricular activities & ++0.86 \\
\hline Position among siblings & $* 0.73$ & Interest paid by the family/ & \\
\hline Mother's presence at home & $* * 0.02$ & Guardian on student's education & +0.08 \\
\hline Private tuition for mathematics & $* * 0.005$ & Ability to concentrate on studies & +0.87 \\
\hline Private tuition for science & $* *<0.001$ & Problems at home (according to student) & +0.13 \\
\hline Extra curricular activities & $* * 0.13$ & Problems at home (according to teacher) & ++0.005 \\
\hline $\begin{array}{l}\text { Time spent for extra curricular activities } \\
\text { (hours per week after school) }\end{array}$ & $* 0.6$ & Height & ++0.005 \\
\hline Educational ambition & $*<0.001$ & Weight & ++0.007 \\
\hline Occupational ambition & $*<0.001$ & & \\
\hline Enthusiasm for studies & & & \\
\hline (according to the student) & $* * 0.001$ & & \\
\hline Enthusiasm for studies (teacher's opinion) & $*<0.001$ & & \\
\hline Hours spent on studies & $*<0.001$ & & \\
\hline Interest paid by the family/ & & & \\
\hline Guardian on student's education & $* 0.001$ & & \\
\hline Ability to concentrate on studies & $* 0.04$ & & \\
\hline Problems at home (according to student) & $* 0.007$ & & \\
\hline Problems at home (according to teacher) & $* *<0.001$ & & \\
\hline Love affairs & $* * 0.71$ & & \\
\hline Personal problems & $* * 0.51$ & & \\
\hline Mental status & $* * 0.66$ & & \\
\hline School attendance & $* 0.03$ & & \\
\hline Height & $* * 0.04$ & & \\
\hline Weight & $* * 0.06$ & & \\
\hline Goitre & $* * 0.25$ & & \\
\hline Intelligence & $* * *<0.001$ & & \\
\hline
\end{tabular}

* F test, ** t test, *** Spearman's correlation coefficient test

+ Kruskal-Wallis test used to determine the significance of difference

++ Mann-Whitney test used to determine the significance of difference

Table 4. Distribution in IQ among iron sufficient and iron deficient students

\begin{tabular}{lccc}
\hline Iron status & $n$ & Mean rank in IQ & $p$ value \\
\hline Iron sufficient & 94 & 87.3 & 0.07 \\
Iron deficient & 94 & 101.7 & \\
Iron sufficient & 58 & 54.7 & 0.22 \\
IDA & 58 & 62.3 & \\
Iron sufficient & 36 & 33.5 & 0.23 \\
ID without A & 36 & 39.5 & \multirow{2}{*}{0.66} \\
Iron sufficient & 12 & 13.1 & \\
Moderate to severe IDA & 12 & 11.9 & \\
\hline
\end{tabular}

*Mann-Whitney $\mathrm{U}$ test used to determine the significance of difference 
Zinc deficiency and iodine deficiency could co-exist with iron deficiency $[9,10]$. Further, deficiency in zinc and iodine may influence cognitive functions $[11,12]$. In spite of the very high prevalence of zinc deficiency expected among South Asian children [13], only 13\% were deficient in zinc in the present study. Only 4 students in the sub sample showed a low free $\mathrm{T}_{4}$ level which is the best indicator reflecting the effect of iodine deficiency on brain function [14]. According to our findings, it is unlikely that the zinc level and the free $\mathrm{T}_{4}$ level would have been confounders in assessing the relationship between iron status and cognitive functions.

Our study showed a number of factors that could affect educational performance and intelligence of Sri Lankan adolescents. There could have been even more undetected factors. This indicates the difficulty to control or explain the effects of all co-variables in a study assessing the relationship between iron status and cognitive functions. Also, the study highlights the difficulty in generalising the findings of one ecological setting to another.

\section{Acknowledgements}

We thank doctors I. Herath, M. Balasooriya, S. Herath, S. Ratnayake and Mr. K. M. C. U. Champika for their help in collecting data. The help received from Miss C. Wijayasiri in processing data is appreciated. This work was supported by a grant from the University of Peradeniya (RG/2003/C-1/10/M).

\section{References}

1. Dissanayake DS, Kumarasiri PVR, Nugegoda DB, Dissanayake DM. Iron status and associated factors among adolescents in the Kandy district. Journal of the Community Physicians of Sri Lanka 2006; 11: 18-24.

2. Cook JD, Skikne BS. Iron deficiency: definition and diagnosis. Journal of Internal Medicine 1989; 226: 349-55.
3. Barney S. Raven Progressive Matrices. Available from: www.li.suu.edu/library/circulation/Barney/psy.

4. Raven Standard Progressive Matrices. Available from: www.cps.nova.edu/ cpphelp/RSPM.html.

5. Soemantri AG, Pollitt E, Kim I. Iron deficiency anaemia and educational achievement. American Journal of Clinical Nutrition 1985; 42: 1221-8.

6. Pollitt E, Hathirat P, Kotchabhakdi NJ, et al. Iron deficiency and educational achievement in Thailand. American Journal of Clinical Nutrition 1989; 50: 687-97.

7. Bruner AB, Joffe A, Duggan AK, et al. Randomised study of cognitive effects on iron supplementation in non-anaemic iron-deficient adolescent girls. Lancet 1996; 348: 992-6.

8. Lynn R, Harland EP. A positive effect of iron supplementation on the IQs of iron deficient children. Personality and Individual Differences 1998; 24: 883-5.

9. Sanstead H. Causes of iron and zinc deficiencies and their effects on brain. Journal of Nutrition 2000; 130: 347s-9s.

10. Zimmerman M, Adou P, Torresani T, et al. Persistence of goiter despite oral iodine supplementation in goitrous children with iron deficiency anaemia in Cote de Ivoire. American Journal of Clinical Nutrition 2000; 71: 88-93.

11. Penland JG. Behavioural data and methodology issues in studies of zinc nutrition in humans. Journal of Nutrition 2000; 130: 361s-364s.

12. United Nations Administrative Committee on Cordination/ Sub Committee on nutrition (ACC/SCN). Allen LH, Gillepsie SR. What works? A review of the efficacy and effectiveness of nutrition interventions. ACC/SCN: Asian Development Bank 2001: 43-54.

13. Brown KH, Wuehler SE, Peerson JM. The importance of zinc in human nutrition and estimation of the global prevalence of zinc deficiency. Food and Nutrition Bulletin 2001; 22: 113-25.

14. Hetzel BS. Iodine deficiency disorders. In: Garrow JS, James WPT, editors. Human nutrition and dietetics. 9th ed. London: Churchill Livingstone,1993: 534-53. 